\title{
The Use of the /ki/ Variant among Young Karakis in Amman and Karak (Jordan) a Comparative Study
}

\author{
Mahmoud El Salman ${ }^{1}$ \\ ${ }^{1}$ King Faisal University, Saudi Arabia \\ Correspondence: Mahmoud El Salman, King Faisal University, Saudi Arabia. E-mail: el_salman@hotmail.com
}

Received: February 28, 2016 Accepted: March 16, 2016 Online Published: March 28, 2016

doi:10.5539/ijel.v6n2p57 URL: http://dx.doi.org/10.5539/ijel.v6n2p57

\begin{abstract}
This article is a sociolinguistic study conducted in Amman and Karak (Jordan) to investigate the linguistic variation in the speech of 48 Karaki informants who are originally from Karak and now living in Amman, and another 48 Karaki informants who still live in Karak. The [ki] variant of the (Vki) variable will be used as a basis to investigate this variation. The study shows that the [ki] is still preserved by the old in Karak and in Amman. It also shows that it is used by the young in a higher percentage than it is in Karak. The exaggeration of the use of it by the young, in contexts where the use of it is not preferable, for example in the presence of other people who do not use it, shows a strong desire to appear as local. It is also an attempt by the young to associate themselves with an area, namely the Karak area, which is known to be socially and politically important in Jordan. Appearing as local is not an aim in itself. It helps to achieve social aims. However, young females do not show the same desire. It disappears from their speech. Appearing as local is not the first priority by them. The rate of using it by them in Karak was in a low percentage. It becomes even lower in Amman. So, it is not uncommon to find women leads in linguistic change and to be innovative in this.
\end{abstract}

\section{Introduction}

This article examines the use of the [ki] variant of the $(\mathrm{K})$ variable in the Arabic dialect of Karak. The dialect of this group is one of the dialects whose phonetic inventory has the variant [ki] of the $(\mathrm{K})$ variable. The people of Karak who fall within the scope of this study are those Jordanians who are originally from Karak (henceforth the Karakis). Huge number of immigrants came to the area as a result of the Arab-Israeli wars in 1948 and 1967. This immigration has noticeably affected Karak society not only demographically but also linguistically. As varieties "change over time" and "varieties are also changed" as Fishman puts it (Fishman, 1972, p. 18) we hypothesize that the dialect of the local group is expected to change due to its contact with another dialect, namely, the dialect of the new comers. Thus, one of the sounds that are considered peculiar to the local group and, thus, symbolizes local identity, is taken to test this hypothesis.

\section{The Town of Karak}

In this section, a background to this sociolinguistic study is provided. The facets of culture involved here are the politics, history, and social customs of Jordan in general and of the Karak district, in particular. Our aim is to characterize a location and its people so as to develop a context for our linguistic study as "mere naturalistic observation of speech behavior is not enough. In order to interpret what he hears, the investigator must have some background knowledge of the local culture and of the processes which generate social meaning. Without this, it is impossible to make generalizations about the social implications" (Blom \& Gumperz, 1972, p. 434). Furthermore, "one cannot understand the development of a language change apart from the social life of the community in which it occurs" (Labov, 1972, p. 3) and sociolinguistic studies "also require a detailed characterization of [the] social and ethnic composition ... geographic features ... population, and culture of the city" (Labov, 2001, p. 41).

The town of Karak is situated on top of a small mountain in the center of the district of that name in southern Jordan (Gubser, 1973, p. 1). The governorate of Karak, of which the district forms part, lies east of the southern half of the Dead Sea in the East Bank of the Kingdom of Jordan.

The Balqa, which includes the town of Madaba, borders it on the north; and to the south lie the district of Tafila and the governorate of Ma'an. The Dead Sea lies to the west and the Syrian (or North Arabian) Desert to the east 
(Gubser, 1973, p. 8). Each of these borders forms a formidable, but not impassable, barrier. The Wadi Al-Mujib and Wadi Al-Hasa, both dropping from heights of $900 \mathrm{~m}$ to well below sea level, are the northern and southern boundaries. The excessively saline water of the Dead Sea cuts off the west, and the east fades into a virtually rainless desert (Gubser, 1973, p. 8).

The district of Karak covers approximately 2,850 square $\mathrm{km}$, with an average elevation of about $770 \mathrm{~m}$. From the east the Syrian Desert rises to form a high limestone plateau, with an average elevation of $1,100 \mathrm{~m}$, and hills which reach $1,300 \mathrm{~m}$, forming the backbone of the area. Then the terrain drops precipitously to the Dead Sea, $395 \mathrm{~m}$ below sea-level.

\section{The Tribe}

As Gubser states, the tribe is the single most important political group in Karak district. Structurally, it may be described as a corporate territorial group with pyramidal and segmentary qualities. The tribes of the area, however, differ considerably in relative size, geographical location, mode of livelihood, and degree of political power. The Karakis, like most Arabs, reckon kinship through the male line. Politically this patrilineal pattern is significant, for it tends to create neat segregated units and subunits within the tribe. A man's identity is more strongly attached to this group than to any other; for the behaviour of an individual is considered to be an extension of that of his kin, and, conversely, the actions of a man's blood relatives heavily reflect upon him (Gubser, 1973).

\section{Amman}

Amman is the capital and most populous city of Jordan, and the country's economic, political and cultural centre. Situated in north-central Jordan, Amman is the administrative centre of the Amman Governorate. It has a population of 4,007,526 and a land area of 1,680 square kilometres (648.7 sq km). Today, Amman is considered to be among the most liberal and westernized Arab cities. It is a major tourist destination in the region, particularly among Arab and European tourists (the free encyclopedia, 2016). People of Jordan, from all parts of the country, come to live in Amman looking for job opportunities. So, contact of dialects is a must in this situation.

\section{Methodology}

The study is empirical in its methods and fully dependent on naturalistic speech. All the interviews, which were conducted in Karak and Amman (Jordan), were made using the face-to-face technique for obtaining data with regard to linguistic variation. The study comprises Jordanians, who are originally from the Karak area. The size of the sample is acceptable and similar to the number of informants in many similar studies, for example the number of informants in Trudgill's (1974) study was 60 in a city with a population of 118, 610, and the number of informants in Daher's study (1998) conducted in Damascus, was 46. Labov also notes that "the structure of social and stylistic variation of language can be studied through samples considerably smaller than those required for the study of other forms of social behaviour" (Labov, 1966, p. 638). The large social network made it possible to draw my sample from both sexes.

This study has been conducted in light of the Labovian Paradigm. The interviews were carried out in shops, houses and universities. This was determined by the possible availability of the informants. The social network framework was followed and the informants were approached in the capacity of "a friend of a friend" or in some cases "a friend of a friend of a friend" (Milroy and Milroy, 1978). Some group conversations were recorded between Karakis where this was possible. The recorded conversations could be considered "a supplementary check on these face-to face tape-recorded interviews" (Labov, 1972, p. 13).

The questions asked in the interviews were designed to provide a challenge for the interviewees' memories in that they depended solely on the Karaki's personal knowledge, and dealt with what they still remembered about the history of the Karak area or remembered hearing from other people.

\section{The (VKi) Variable}

The (Vki) variable has three variants. These are [ik], [ki] and [vki]. The [ki] variant is the local variant used by Karakis while the [ik] variant is the non-local variant used by Fallahis and it is also the variant used in the UAD (urban Arabic dialect. The SA variant is [vki]. The initial V in (Vki) indicates vowel. In Standard Arabic this vowel can be [u], [a] or [i] depending on the final vowel of the preceding element. In the case of nouns, this final vowel will be a case-ending. Standard Arabic has three cases; nominative, which is most commonly expressed by the vowel suffix $-u$; accusative, which is most commonly expressed by the vowel suffix $-a$; and genitive, which is most commonly expressed by the vowel suffix $-i$. Thus, in /kayfa SiHHatuki/ "how is your health?" (Literally "how health your"), SiHHa (tu) "health" is in the nominative case, and accordingly has $-u$ before the 
pronoun suffix proper $-k i$. The preposition $f i$; however, like all prepositions in Standard Arabic, takes the genitive case. Thus, the form for 'in your house' is /fi baytiki/, /bayt/ 'house', with the genitive -i vowel before the pronoun suffix proper [ki]. In the non-local colloquial, this second person feminine singular suffix is always realised as [ik] and in the local colloquial it is always realised as [ki].

\section{The (K) Variable Used by Karakis: Findings and Discussion}

In this section the use of the $(\mathrm{K})$ variable by the people of Karak is discussed. Table 1 shows the distribution of informants by sex and age.

Table 1. Distribution of informants by sex and age

\begin{tabular}{llll}
\hline \multicolumn{1}{c}{ Sex } & M & F & Total \\
\hline Young & 8 & 8 & 16 \\
Middle & 8 & 8 & 16 \\
Old & 8 & 8 & 16 \\
\hline Total & 24 & 24 & 48 \\
\hline
\end{tabular}

Table 2. The distribution of the variable (VKi) by age and sex in Karak

\begin{tabular}{lllllll}
\hline Sex & M & & F & & N \\
Age & [ki]\% & [ik]\% & N & {$[\mathbf{k i}] \%$} & [ik]\% & 360 \\
Young & 79 & 21 & 400 & 8 & 92 & 411 \\
Middle & 75 & 25 & 430 & 91 & 9 & 420 \\
Old & 88 & 12 & 492 & 80 & 20 & \\
\hline
\end{tabular}

Table 3. The distribution of the variable (VKi) by age and sex in Amman .

\begin{tabular}{lllllll}
\hline Sex & M & & F & & N \\
Age & {$[\mathbf{k i}] \%$} & {$[\mathbf{i k ]} \%$} & $\mathbf{N}$ & {$[\mathbf{k i}] \%$} & {$[\mathbf{i k}] \%$} & 300 \\
Young & 90 & 10 & 400 & 2 & 98 & 379 \\
Middle & 80 & 20 & 430 & 40 & 60 & 412 \\
Old & 87 & 13 & 492 & 70 & 30 & \\
\hline
\end{tabular}

Table 2 shows that the/ ki/ variant was used in a very high percentage in the speech of young males in Amman. The percentage reaches $90 \%$. In other words, it exceeds the percentage found among young Karakis in Karak. In the attempts to interpret this strange trend, it was found out that confirming local identity is the major reason. In Karak, it was found out to be $79 \%$ in the speech of young males. There, the name of the tribe could be considered enough to confirm this identity-Karaki. Everybody knows the social contexts and the tribe found in the area. In addition, they all belong to the same speech community in Karak. Speech community "comprises people who are in habitual contact with each other by means of speech which involves either a shared language variety or shared was of interpreting the different language varieties commonly used in the area (Mesthrie et al., 2000 , p. 38). So, the exaggeration in the use of this peculiar Karaki variant by any member does not work; the aim of using it would be easily interpreted and understood. The prestige of being local that might be attached to its user is already had by the rest of the members; they are all Karakis. Amman is not the Karak area. As a capital, it is expected to find people of different origins living in it. Karak is an important political city in Jordan (many military and political leaders are originally from this city). The language is found to be needed more to confirm this identity. Thus, it is not unexpected to find the young hypercorrect in using it even in context where linguistic accommodation is expected; using it in the presence of people who do not use it. Hypercorrection is an attempt to exaggerate in the use of the prestigious variant as a result of a tendency to use the pronunciation considered correct and appropriate in a given context (Mesthrie et al., 2000). This exaggeration is noticed in the speech of two young judges talking to one another. Some individual cases will be illustrated throughout the study because "even though most choices reflect some societal pattern, speakers make linguistic choices as individuals. That is, choices ultimately lie with the individual and are rationally based" (Myers-Scotton \& Bolonyal, 2001, p. 1). Confirming locality is not an aim in itself. It does not also play role in getting a good position in the local community. It is believed that their attempt to adopt the locals' way of speech in a very high percentage is an attempt to enhance and justify the right to have a high position. In other words, this way of speaking does not in itself get them appointed to a particular post but might be used by them to justify this appointment, in which case 
it is to be considered psychological rather than practical. It is also believed that the use of this very Karaki variant is used by the young as it is a linguistic feature which carries the social meaning of locality and symbolizes Jordanian identity with some kind of prestige as it is the variant used in a city which is known to play a very important role in the political life of Jordan (Gubser, 1973). Indeed, it is not uncommon for Karakis to adopt the local variant "as dialects symbolise ... local cultures, and help to maintain and defend them" (Trudgill, 2002, p. 29). They use this variant because it is the variant of power and they are at an age where competition with other local people over daily affairs in the capital Amman, such as job opportunities for which local identity is very important, is at its highest level. And this might interpret why it is used by some people who are known to occupy high ranks. The use of this very karaki variant presents a "high degree of social awareness" and is well-recognized as a "linguistic marker" (Labov, 2001, p. 196). It seems that this peculiarity enhances its social significance, defined by Blom \& Gumperz (1972, p. 417) as "the social value implied when an utterance is used in a certain context", and makes it a target for the young to whom such a value is extremely significant (Labov, 2001, p. 196). This case is repeated in the speech of two other doctors. The use of the local variant was clearly noticed in their speech. Their very high level of education enables them to use even the standard variant, or at least the neutral variant, namely, the /ik/. But the deliberate use of the Karaki alternate was easily observed. It was even used with words classified as lexically conditioned, where the SA variant is favored with them (see also Abd al Jawad, 1981, Al Khatib, 1988). In other words, with words which are normally used with the standard Arabic variant. A word like/thaqafa/ is normally used with the standard variant. One of the speakers said while talking to a university female student: / thaqaftki laysat 3allya/ "your education is not that good". He should have said: /thaqafatoki/. It was clearly noticed that Scotton's "cost and reward" principle operates here (Scotton, 1995). Appearing as local provides access to power, which is the 'reward' and is more important than not appearing as prestigious, which is the "cost".

Table 2 shows that the [ki] variant of the $(\mathrm{K})$ variable occurs in $75 \%$ of middle aged male's utterances in Karak. Table 3 shows that the use of it also increases in the speech of the middle aged group in Amman. It became 80\%. The middle aged group are still in an age where ambition to achieve something social or political still exists. As a result, appearing as local is still important. While the use of it among middle aged male group in Karak was $75 \%$, it became $80 \%$ in Amman.

It is worth noticing that the percentage of the use of it by old male remains almost as it is $87 \%$ in Amman, and in Karak it was $88 \%$. The use of it whether in Karak or Amman, does not happen in order to achieve something social. They used to use this variant and they do not have any motive in this age to change it. Le Page (1997) notes that an individual's tendency toward language shift could be constrained by four factors, among which is age. According to Page, "Individuals create their linguistic systems so as to resemble those of the group or groups they wish from time to time to be identified with, or so as to distinguish themselves from those they wish to distance themselves from. Their success in doing so is subject to constraints ... [such as] the strength of their motivation, which is likely to be multidimensional; and their ability to change their behaviour-possibly mainly a function of age" (Le Page, 1997, pp. 28-29).

The linguistic behavior of the young female informants is also worth being observed. It was low in Karak and it became even lower in Amman. They were 8\% and 2\%, respectively. Even in the speech of old female the percentage of the use of the local variant $/ \mathrm{ki} /$ decreases. It was $80 \%$ in Karak, and it became $70 \%$ in Amman. Thus, innovation can be noticed even among old females. In other words, while the percentage of using it remains almost the same among old male informants, the percentage of using it decreases in the speech of old female speakers. Therefore, Sex was a very significant factor in the use of [ki] in Amman. The determining factor, therefore, is age. It is a very well documented fact that the elderly are subject to much more pressure from their society to preserve their native dialect than the young (Walter, 1991, p. 201). Eckert also reports that "community studies of variation frequently show that increasing age correlates with increasing conservatism in speech" (Eckert, 1997, p. 157). But it seems that the social pressure to preserve the local Karaki variant in Amman decreases. As a result, the suppress desire to use a variant which has some kind of prestige for female informants emerges in Amman when the local pressure disappears as a result of migrating to Amman.

SPSS analysis confirms that age has very powerful significance in the use of [ki] variant (the threshold for significance is $\mathrm{p}<.05$ while $\mathrm{p}<.000$ for age in the use of [ki]) in Karak. SPSS does not show the same significance when age is considered in Amman. Both old male informants and young speakers use it in a high percentage. The difference was only in the aim of using it. . SPSS analysis shows that sex has a very low significance for the use of the [ki] among the elderly in Karak. ( $\mathrm{P}<.05$ while $\mathrm{P}<.278$ for sex in the use of the [ki] among the elderly), while sex was a very significant factor in the use of [ki] in Amman. . 


\section{Conclusion}

The study shows a comparison in the use of the / ki/ variant of the (Vki) variable in the Karak area, where it is originally used, and Amman, where some Karakis who are originally from Karak live. The local Karaki variant is used in a high percentage by the elderly in the Karak area. It remains as it is in the speech of the elderly who live in Amman. The elderly tend to preserve the old dialects as a result of the social pressure exerted on them by the society to preserve old linguistic forms. The percentages of using it increase in the speech of the young male and the middle-aged male groups in Amman. For example, while the rates were $79 \%$ by the young and $75 \%$ by the middle aged groups in the Karak area, respectively; the percentages became $90 \%$ and $80 \%$ in Amman. Cost and reward principle suggested by Scotton, was found to be the major reason for this linguistic behaviour. The reward sought by the young is to appear as local. A variant which is known to be the variant of an area known to be very important politically and socially like the Karak area, will be the best tool to achieve this. So, this study shows that people frequently rely on linguistic tools to achieve social aims, for example achieve local group membership.

Young female group linguistically appears again to be the innovative group. Appearing as local is not their first priority. Their priority is to appear as urbanized and soft through the use of the variant that is used more in Amman. Thus, the study shows that they abandoned the Karaki variant in favour of the variant used in Amman. While the percentage was $8 \%$ it became $2 \%$ in Amman.

\section{References}

Abdel-Jawad, H. (1981). Lexical and Phonological Variation in Spoken Arabic in Amman. University of Pennsylvania dissertation.

Al Khatib, M. (1988). Sociolinguistic change in an expanding urban contex. A case study of Irbid city, Jordan. $\mathrm{PhD}$ thesis, University of Durham.

Blom, J. P., \& Gumperz, J. J. (1972). Social meaning in linguistic structures: code-switching in Norway. In J. J. Gumperz \& D. Hymes (Eds.), Directions in Sociolinguistics (vol. 1, pp. 407-434). New York: Oxford Press.

Daher, J. (1998). Gender in Linguistic Variation: The Variable (Q) In Damascus Arabic. In E. Benmamoun, M. Eid, \& N. Haeri (Eds.), Perspectives on Arabic Linguistics (vol. XI, pp. 183-205). Amsterdam: Benjamins Publishing Company. http://dx.doi.org/10.1075/cilt.167.13dah

Eckert, P. (1997). Age as a Sociolinguistic Variable. In F. Coulmas (Ed.), The Handbook of Sociolinguistics (pp. 151-168). Oxford: Blackwell.

Fishman, J. A. (1972). The sociology of language. Rowley: Newbury house.

Gubser, P. (1973). Politics and Change in Al-Karak, Jordan. Oxford: Oxford University Press.

Labov, W. (1966). The social stratification of English in NewYork City. Washington, DC: Centre for Applied Linguistics.

Labov, W. (1972). Sociolinguistic Patterns. Philadelphia: University of Pennsylvania Press.

Labov, W. (2001). Principle of Linguistic change, 2. Oxford: Blackwell.

Le Page, R. (1997). The evolution of a sociolinguistic theory of language. In F. Coulmas (Ed.), The Handbook of socio-linguistics (vol. 1, pp. 15-32). Oxford: Blackwell.

Mesthrie, R. (2000). Clearing the ground: basic issues, concepts and approaches. In R. Mesthrie, J. Swann, A. Deumert, \& W. Leap (Eds.), Introducing Sociolinguistics (pp. 1-43). Edinburgh: Edinburgh University Press.

Milroy, J., \& Milroy, L. (1978). Belfast: Change and variation in an urban vernacular. In Trudgill (Ed.), pp. 19-36.

Myers-Scotton, C. (1995). Social Motivations for Code Switching: Evidence from Africa. Oxford: Clarendon Press.

Myers-Scotton, C. M., \& Bolonyal, A. (2001). Calculating speakers: Code-switching in a rational choice model. Language in Society, 30, 1-28. http://dx.doi.org/10.1017/S0047404501001014

Trudgill, P. (1974). The Social Differentiation of English in Norwich. Cambridge: Cambridge University Press

Trudgill, P. (2002). Sociolinguistic variation and change. Edinburgh: Edinburgh University Press.

Walters, K. (1991). Women, Men, and Linguistic variation in the Arab world. In B. Comrie \& M. Eid (Eds.), 
Perspectives on Arabic Linguistics (vol. III, pp. 197-229). Amsterdam: John Benjamins Publishing Company. http://dx.doi.org/10.1075/cilt.80.14wal

\section{Copyrights}

Copyright for this article is retained by the author(s), with first publication rights granted to the journal.

This is an open-access article distributed under the terms and conditions of the Creative Commons Attribution license (http://creativecommons.org/licenses/by/3.0/). 